\title{
MoCA Test: normative and diagnostic accuracy data for seniors with heterogeneous educational levels in Brazil
}

\author{
Teste MoCA: dados normativos e de acurácia diagnóstica para idosos com níveis \\ educacionais heterogêneos no Brasil
}

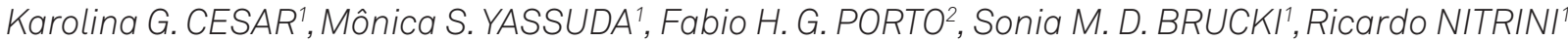

\begin{abstract}
The Montreal Cognitive Assessment (MoCA) has been described as a good tool to detect cognitive impairment. The ideal MoCA cutoff score is still under debate. The aim was to provide MoCA norms and accuracy data for seniors with a lower education level, including illiterates. Methods: Data originated from an epidemiological study conducted in the municipality of Tremembé, Brazil. The Brazilian MoCA test was applied as part of the cognitive assessment in all participants. Of the 630 participants, 385 were classified as cognitively normal (CN) and were included in the normative data set, 110 individuals were diagnosed with dementia and 135 were classified as having cognitive impairment no dementia (CIND). Results: The total scores varied significantly according to age and education among the three diagnostic groups: CN, CIND and dementia ( $p<0.001$ ). To distinguish participants with CN from dementia, the best MoCA cutoff was 15 points (sensitivity $90 \%$, specificity $77 \%$ ) and to differentiate those with CN from CIND, the MoCA cutoff was 19 points (sensitivity 84\%, specificity 49\%). Those scores varied according to education level. Conclusions: The MoCA test did not have a high accuracy for detecting CIND in the population with a low educational level. Nevertheless, this tool may be used to detect dementia, especially in individuals with more than five years of education, if a lower cutoff score is adopted.
\end{abstract}

Keywords: Dementia; epidemiology; mass screening; cognitive dysfunction.

\section{RESUMO}

O Montreal Cognitive Assessment (MoCA) foi descrito como uma boa ferramenta para detectar comprometimento cognitivo. A nota de corte ideal do MoCA ainda está em debate. O objetivo é fornecer normas do MoCA e dados de acurácia para idosos dentro de uma faixa educacional mais baixa, incluindo analfabetos. Métodos: Os dados foram provenientes do estudo epidemiológico realizado no município de Tremembé, Brasil. A versão brasileira do MoCA foi aplicada como parte da avaliação cognitiva em todos os participantes. Dos 630 participantes, 385 foram classificados como cognitivamente normais (CN) e foram incluídos no conjunto de dados normativos, 110 indivíduos foram diagnosticados com demência e 135 foram classificados como tendo comprometimento cognitivo sem demência (CCSD). Resultados: Os escores totais variaram significativamente de acordo com a idade e escolaridade entre os três grupos diagnósticos: CN, CCSD e demência ( $p<0,001)$. Para distinguir CN de demência, a melhor nota de corte do MoCA foi de 15 pontos (sensibilidade 90\%, especificidade 77\%) e para diferenciar o grupo CN de CCSD, a nota de corte do MoCA foi de 19 pontos (sensibilidade 84\%, especificidade 49\%). Essas notas de corte variaram conforme o nível de escolaridade. Conclusões: 0 teste MoCA não teve alta acurácia para detectar CCSD nesta população de baixa escolaridade. No entanto, esta ferramenta poderia ser usada para detectar demência, especialmente em indivíduos com mais de 5 anos de escolaridade, se uma menor nota de corte fosse adotada.

Palavras-chave: Demência; epidemiologia; programas de rastreamento; disfunção cognitiva.

The Montreal Cognitive Assessment (MoCA) is a neuropsychological tool that requires approximately 15 minutes to assess the following domains: attention, executive functions, memory, language, visuoconstructional skills, and orientation. ${ }^{1}$ The MoCA test was created as a screening test to detect mild cognitive impairment (MCI) with a cutoff score of 26 points in

${ }^{1}$ Universidade de São Paulo, Departamento de Neurologia, Unidade de Neurologia Cognitiva e Comportamental, São Paulo SP, Brasil; ${ }^{2}$ Universidade de São Paulo, Departamento de Psiquiatria, Laboratório de Neuroimagem Psiquiátrica (LIM 21), São Paulo SP, Brasil.

Study conducted by the Department of Neurology, University of São Paulo Medical School, Brazil

Correspondence: Karolina G. Cesar; Av Armando Salles de Oliveira, 200 / apto. 42; 12030-080 Taubaté SP, Brasil; E-mail:karolgcesar@gmail.com Karolina Cesar iD https://orcid.org/0000-0001-9617-9567; Monica S. Yassuda iD https://orcid.org/0000-0002-9182-2450; Fabio H. Gobi Porto iD https:// orcid.org/0000-0002-3705-9693;Sonia Maria D. Brucki (iD) https://orcid.org/0000-0002-8303-6732; Ricardo Nitrini iD https://orcid.org/0000-0002-5721-1525 Conflict of interest: There is no conflict of interest to declare.

Received 07 January 2019; Received in final form 11 June 2019; Accepted 01 July 2019.

Support: We are grateful to the Brazilian Institute of Geography and Statistics (IBGE) for the support and to the elderly population of Tremembé for their commitment. The epidemiological study of Tremembé was supported by the FAPESP (Fundação de Amparo a Pesquisa do Estado de São Paulo) grant number 2012/04815-6. 
a total score of $30^{1}$. The MoCA has consistently shown superior properties compared with the Mini-Mental State Examination (MMSE), and higher diagnostic accuracy in discriminating between MCI and Alzheimer's disease patients².

A significant proportion of the elderly population has a cognitive status that cannot be classified as normal or dementia, hence terms such as MCI and cognitive impairment, no dementia (CIND) have been used ${ }^{3}$. Mild cognitive impairment is defined as the presence of cognitive complaint, cognitive decline (memory and/or other domains) and preserved functional abilities ${ }^{4}$. The concept of CIND is more comprehensive because, in addition to encompassing the concept of MCI, it also includes individuals who have a cognitive performance below that expected for their age and education even if no decline is reported ${ }^{3}$.

Studies have shown that the MoCA test has high diagnostic accuracy for MCI and mild dementia among individuals living in high-income countries who frequently have around 12 years of education ${ }^{5,6}$. However, other studies have shown that age and lower education can impact the score ${ }^{2,7,8}$; and the 1-point addition to the score for individuals with $\leq 12$ years of education has been regarded as insufficient for the educational differences adjustment?

The ideal MoCA cutoff score for MCI is still being debated. In a recent systematic review and meta-analysis of the literature to determine the diagnostic accuracy of the MoCA to differentiate cognitively unimpaired individuals from possible MCI demonstrated that the $\leq 25$-point cutoff could lead to a high rate of false positives; therefore, the authors suggested a cutoff of $\leq 22$ points. In the eight studies selected for this review, the minimal mean education found was 8.9 years ${ }^{9}$.

The Brazilian version of the MoCA was initially validated in a clinical sample of older adults with an education of four years and higher, and a cutoff score of 25 points generated a sensitivity and specificity for MCI of $81 \%$ and $77 \%$, respectively ${ }^{10}$. Nevertheless, in this study, the mean education was 11.42 years; therefore, the sample was not representative of older Brazilian adults.

A recent Brazilian study, including a wider range of educational levels, used the more conservative suggestion cited above ( $\leq 22$ points) and found that $67 \%$ of their control sample was regarded as cognitively impaired. Therefore, the need to adjust MoCA cutoffs according to schooling levels in populations with heterogeneous educational backgrounds was highlighted $^{11}$. A Colombian study has also shown that MoCA scores were highly influenced by education: mean MoCA scores among the cognitively unimpaired were 16 points for illiterates, 18 for those with incomplete primary school, and 20 for those with complete primary school ${ }^{12}$.

The aim of the present study was to provide MoCA norms for seniors with lower education, including illiterates, with the sample stratified into groups of age and education. An additional aim was to examine the accuracy of the MoCA to detect dementia and CIND in a sample with a low educational background.

\section{METHODS}

\section{Participants}

The MoCA test was applied as part of the cognitive evaluation of a single-phase cross-sectional epidemiological study, in which home visits were carried out in the municipality of Tremembé, located in the state of São Paulo, Brazil. The participants were randomly selected and more details regarding this primary study, that initially had the objective of estimating the prevalence of cognitive impairment (CIND and dementia), can be found in César et al. ${ }^{13}$. The MoCA results were not used to establish the diagnosis of cognitive impairment and its scores were unknown by those involved in the consensus meetings for diagnosis.

The sample for the present study included 630 seniors 60 years or older, with 385 being classified in the primary epidemiological study as cognitively normal (CN), 135 as CIND and 110 as having dementia. We excluded eight individuals among the 110 participants with dementia because they had severe dementia. Of the remaining dementia participants, the great majority (88\%) had a Clinical Dementia Rating (CDR) score of 1 , and $12 \%$ had a CDR score of 2 .

\section{Assessment protocol}

The protocol was completed in a single visit in which the entire assessment, including history taking, physical and neurological examination, cognitive assessment, psychiatric and functional evaluation, was completed. The Brazilian version of the $\mathrm{MoCA}^{10}$ was applied as part of the cognitive assessment in all participants. Education was defined by the number of years of education attained, and individuals were considered illiterates when they reported they could not read and write or had less than one year of education, and in both cases they were also unable to read the phrase "close your eyes" of the MMSE. For individuals with $\leq 12$ years of education, one point was added to the total score. ${ }^{10}$

\section{Clinical diagnoses}

The diagnoses were established in consensus meetings during the primary phase of the epidemiological study and participants were classified as CN, CIND, or dementia.

Dementia was diagnosed based on clinical criteria reported by the National Institute on Aging and Alzheimer's Association $^{14}$ for the diagnosis of all-cause dementia and on the recommendations of the Brazilian Academy of Neurology ${ }^{15}$. Besides the presence of cognitive decline in the clinical history, participants had cognitive test results below educationadjusted cutoff scores in at least two domains (two cognitive domains or one cognitive plus behavioral problems), plus high scores in the Informant Questionnaire on Cognitive Decline in the Elderly ${ }^{16,17}$ and in the Functional Activities Questionnaire ${ }^{18}$. The cognitive tests that were considered for diagnoses were: the MMSE ${ }^{19,20}$, the delayed recall of the drawings from the Brief Cognitive Screening Battery ${ }^{21}$, the Clock Drawing Test and the Semantic Verbal Fluency Test animal category ${ }^{22,23}$. 
The CIND diagnostic criteria were based on medical history, performance in cognitive tests below educationadjusted cutoff scores, irrespective of the presence of a cognitive complaint, and absence of functional impairment. The presence of a cognitive complaint by the individual and/or informant is necessary for the MCI Petersen criteria, but it is not necessary for CIND; therefore, the CIND diagnosis comprised all individuals with mild impairment ${ }^{4}$.

The study was approved by the University of São Paulo Medical School Ethics Committee (protocol 0378/09) and the authors have no conflict of interest with any commercial or other associations in connection with the submitted article.

\section{Statistical analysis}

Statistical analysis was performed using the Statistical Package for the Social Sciences version 17.0 (SPSS Inc., Chicago, IL, USA). Analysis of variance (ANOVA) was used to compare MoCA scores (total and subtest scores) with the sample stratified into groups of age and education and the Bonferroni post hoc test was used to identify the differences among education levels in the cognitively normal group. The MMSE scores were also compared using ANOVA. Significance was set at $\mathrm{p}<0.05$. Diagnostic accuracy was assessed with receiver operating characteristic (ROC) curve analyses, which provided scores for the area under the curve, sensitivity and specificity. The MoCA scores were also divided according to educational level. The Youden Index (J), the maximum potential effectiveness of a diagnostic test, was used as a summary measure of the ROC curve. The Youden
Index is defined as the maximum value of [sensitivity + (specificity -1)], indicating the best combinatory index of sensitivity and specificity at a determined cut-point.

\section{RESULTS}

\section{Normative data}

In Table 1, the MoCA mean scores are presented according to age, education, and sex, with the sample stratified into diagnostic groups. The MoCA total scores varied significantly according to age, education, and sex, in all diagnostic groups, except according to sex in the dementia group.

Of the 630 participants of this study, 385 were classified as $\mathrm{CN}$ and provided the normative data. In the $\mathrm{CN}$ sample, there was a higher prevalence of women (65.7\%), of younger seniors 60-64 years (30.1\%) and low educational level (1-4 years) $(49.1 \%)$. The MoCA mean total score in the CN group was $19.06( \pm 3.18)$, while the MMSE was $25.23( \pm 3.18)$.

Table 2 presents the norms for MoCA subtest scores stratified into educational levels within each age group. Subtest scores varied significantly according to the educational level of the sample $(\mathrm{p}<0.001)$. Table 3 presents the MoCA and MMSE total scores stratified into educational levels within each age group, and they varied significantly according to education. Table 4 presents total and subdomain scores for the MoCA and the total scores for the MMSE, with the sample stratified only in different educational levels.

Table 1. MoCA mean scores according to age, education, and sex with the sample stratified into diagnostic groups from the Tremembé epidemiological study.

\begin{tabular}{|c|c|c|c|}
\hline Variable & $\mathrm{CN}(\mathrm{n}=385)$ & $\operatorname{CIND}(n=135)$ & DEMENTIA $(n=102)$ \\
\hline MoCA & $19.06 \pm 4.88$ & $15.09 \pm 4.57$ & $10.04 \pm 4.56$ \\
\hline MMSE & $25.23 \pm 3.18$ & $22.53 \pm 3.63$ & $16.64 \pm 6.59$ \\
\hline \multicolumn{4}{|l|}{ Age - years } \\
\hline $60-64(n=152)$ & $19.68 \pm 5.26(n=116)$ & $15.86 \pm 3.12(n=28)$ & $12.50 \pm 6.21(n=8)$ \\
\hline $65-69(n=152)$ & $20.10 \pm 4.39(n=112)$ & $15.46 \pm 4.73(n=24)$ & $11.69 \pm 4.48(n=16)$ \\
\hline $70-74(n=116)$ & $18.52 \pm 4.42(n=67)$ & $14.41 \pm 4.03(n=32)$ & $10.53 \pm 3.66(n=17)$ \\
\hline $75-79(n=99)$ & $18.27 \pm 5.17(n=49)$ & $17.00 \pm 5.33(n=25)$ & $10.68 \pm 4.45(n=25)$ \\
\hline $80-84(n=62)$ & $17.19 \pm 3.96(n=27)$ & $13.82 \pm 4.57(n=17)$ & $8.61 \pm 3.36(n=18)$ \\
\hline$\geq 85(n=41)$ & $13.79 \pm 4.86(n=14)$ & $8.24 \pm 4.89(n=9)$ & $5.93 \pm 2.55(n=18)$ \\
\hline p-value & $p<0.001$ & $p=0.013$ & $p=0.002$ \\
\hline \multicolumn{4}{|l|}{ Education - years } \\
\hline $0(n=86)$ & $12.09 \pm 3.94(n=46)$ & $10.14 \pm 2.53(n=21)$ & $6.26 \pm 2.47(n=19)$ \\
\hline $1-4(n=341)$ & $18.04 \pm 3.68(n=189)$ & $14.65 \pm 3.60(n=83)$ & $10.70 \pm 4.31(n=69)$ \\
\hline $5-8(n=83)$ & $20.92 \pm 3.32(n=62)$ & $19.08 \pm 4.19(n=13)$ & $11.75 \pm 3.99(n=8)$ \\
\hline $9-11(n=51)$ & $23.18 \pm 2.76(n=40)$ & $19.33 \pm 4.27(n=9)$ & $12.00 \pm 9.90(n=2)$ \\
\hline$\geq 12(n=61)$ & $23.98 \pm 2.11(n=48)$ & $20.67 \pm 3.00(n=9)$ & $12.25 \pm 7.36(n=4)$ \\
\hline p-value & $p<0.001$ & $p<0.001$ & $p=0.001$ \\
\hline \multicolumn{4}{|l|}{ Sex } \\
\hline Women $(n=393)$ & $18.58 \pm 4.99(n=253)$ & $14.28 \pm 4.20(n=82)$ & $9.47 \pm 4.39(n=58)$ \\
\hline $\operatorname{Men}(n=229)$ & $19.98 \pm 4.55(n=132)$ & $16.34 \pm 4.87(n=53)$ & $10.80 \pm 4.71(n=44)$ \\
\hline p-value & $p=0.007$ & $p=0.010$ & $p=0.145$ \\
\hline
\end{tabular}

CN: cognitively normal; CIND: cognitive impairment, no dementia; n: number of participants; MoCA: Montreal Cognitive Assessment; MMSE: Mini-Mental State Examination; $p$-value refers to ANOVA, all groups differ $=p<0.001$. 
Table 2. Subtest scores for the Brazilian MoCA, by age and education level in cognitively normal participants.

\begin{tabular}{|c|c|c|c|c|c|c|c|c|c|c|c|c|c|c|c|}
\hline \multirow{4}{*}{ Variable } & \multicolumn{15}{|c|}{ Education (years) } \\
\hline & \multicolumn{5}{|c|}{ Age $60-64$ years } & \multicolumn{6}{|c|}{ Age $65-69$ years } & \multicolumn{4}{|c|}{ Age $70-74$ years } \\
\hline & 0 & $1-4$ & $5-8$ & $9-11$ & $\geq 12$ & 0 & $1-4$ & $5-8$ & $9-11$ & $\geq 12$ & 0 & $1-4$ & $5-8$ & $9-11$ & $\geq 12$ \\
\hline & $\overline{n=12}$ & $n=49$ & $n=22$ & $n=15$ & $n=18$ & $\overline{n=10}$ & $\overline{n=49}$ & $\overline{n=24}$ & $n=12$ & $\mathrm{n}=17$ & $\mathrm{~N}=7$ & $\overline{n=34}$ & $\overline{n=13}$ & $\mathrm{~N}=7$ & $n=6$ \\
\hline \multicolumn{16}{|c|}{ Visuospatial / executive } \\
\hline Mean & 1.17 & 2.57 & 2.86 & 3.60 & 4.06 & 1.00 & 2.29 & 2.58 & 3.17 & 4.12 & 1.43 & 1.97 & 2.54 & 3.86 & 3.27 \\
\hline SD & 0.72 & 1.29 & 1.12 & 1.06 & 1.16 & 0.47 & 1.09 & 1.25 & 1.03 & 1.17 & 0.53 & 0.87 & 1.05 & 0.90 & 1.03 \\
\hline Min/Max & $0 / 3$ & $0 / 5$ & $1 / 5$ & $2 / 5$ & $2 / 5$ & $0 / 2$ & $1 / 5$ & $1 / 5$ & $2 / 5$ & $1 / 5$ & $1 / 2$ & $1 / 4$ & $1 / 5$ & $3 / 5$ & $2 / 5$ \\
\hline \multicolumn{16}{|l|}{ Naming } \\
\hline Mean & 1.75 & 2.35 & 2.50 & 2.60 & 2.72 & 1.90 & 2.45 & 2.54 & 2.58 & 2.82 & 2.43 & 2.18 & 2.46 & 3.00 & 2.67 \\
\hline $\mathrm{SD}$ & 0.62 & 0.52 & 0.80 & 0.51 & 0.46 & 0.57 & 0.68 & 0.51 & 0.51 & 0.39 & 0.53 & 0.63 & 0.66 & 0 & 0.52 \\
\hline Min/Max & $1 / 3$ & $1 / 3$ & $0 / 3$ & $2 / 3$ & $2 / 3$ & $1 / 3$ & $0 / 3$ & $2 / 3$ & $2 / 3$ & $2 / 3$ & $2 / 3$ & $0 / 3$ & $1 / 3$ & $3 / 3$ & $2 / 3$ \\
\hline \multicolumn{16}{|l|}{ Attention } \\
\hline Mean & 1.25 & 3.94 & 4.50 & 4.73 & 5.39 & 1.70 & 4.16 & 5.04 & 5.08 & 5.82 & 2.43 & 3.71 & 4.15 & 5.43 & 4.83 \\
\hline SD & 1.54 & 1.75 & 1.10 & 1.22 & 0.92 & 1.16 & 1.39 & 0.95 & 1.16 & 0.39 & 1.62 & 1.55 & 1.21 & 0.53 & 0.75 \\
\hline Min/Max & $0 / 5$ & $0 / 6$ & $3 / 6$ & $2 / 6$ & $3 / 6$ & $0 / 4$ & $1 / 6$ & $2 / 6$ & $3 / 6$ & $5 / 6$ & $0 / 5$ & $0 / 6$ & $2 / 6$ & $5 / 6$ & $4 / 6$ \\
\hline \multicolumn{16}{|l|}{ Language } \\
\hline Mean & 0.42 & 1.29 & 1.23 & 1.93 & 2.33 & 0.70 & 1.43 & 1.50 & 1.92 & 2.12 & 0.86 & 1.21 & 1.23 & 2.57 & 2.17 \\
\hline SD & 0.79 & 0.82 & 0.87 & 0.79 & 0.59 & 0.67 & 0.89 & 0.78 & 0.51 & 0.69 & 0.90 & 0.81 & 1.09 & 0.53 & 0.98 \\
\hline Min/Max & $0 / 2$ & $0 / 3$ & $0 / 3$ & $1 / 3$ & $1 / 3$ & $0 / 2$ & $0 / 3$ & $0 / 3$ & $1 / 3$ & $1 / 3$ & $0 / 2$ & $0 / 3$ & $0 / 3$ & $2 / 3$ & $1 / 3$ \\
\hline \multicolumn{16}{|l|}{ Abstraction } \\
\hline Mean & 0.17 & 0.59 & 0.86 & 1.00 & 1.50 & 0 & 0.53 & 1.04 & 1.08 & 1.47 & 0.14 & 0.50 & 1.31 & 1.86 & 1.67 \\
\hline SD & 0.39 & 0.76 & 0.83 & 0.93 & 0.71 & 0 & 0.74 & 0.86 & 0.79 & 0.87 & 0.38 & 0.61 & 0.85 & 0.38 & 0.82 \\
\hline Min/Max & $0 / 1$ & $0 / 2$ & $0 / 2$ & $0 / 2$ & $0 / 2$ & $0 / 0$ & $0 / 2$ & $0 / 2$ & $0 / 2$ & $0 / 2$ & $0 / 1$ & $0 / 2$ & $0 / 2$ & $1 / 2$ & $0 / 2$ \\
\hline Delayed reca & & & & & & & & & & & & & & & \\
\hline Mean & 1.25 & 0.90 & 2.14 & 1.80 & 2.17 & 0.50 & 1.31 & 1.63 & 1.92 & 2.18 & 0.71 & 0.76 & 1.54 & 1.14 & 0.83 \\
\hline $\mathrm{SD}$ & 1.91 & 1.53 & 1.69 & 1.57 & 1.72 & 1.08 & 1.45 & 1.66 & 1.16 & 1.47 & 1.49 & 1.33 & 1.33 & 1.86 & 0.98 \\
\hline Min/Max & $0 / 5$ & $0 / 5$ & $0 / 5$ & $0 / 4$ & $0 / 5$ & $0 / 3$ & $0 / 4$ & $0 / 4$ & $0 / 4$ & $0 / 5$ & $0 / 4$ & $0 / 5$ & $0 / 3$ & $0 / 5$ & $0 / 2$ \\
\hline Orientation & & & & & & & & & & & & & & & \\
\hline Mean & 4.75 & 5.86 & 5.82 & 5.87 & 6.00 & 5.70 & 5.80 & 5.92 & 5.75 & 5.88 & 5.00 & 5.62 & 5.92 & 6.00 & 6.00 \\
\hline $\mathrm{SD}$ & 1.42 & 0.35 & 0.39 & 0.35 & 0 & 0.48 & 0.46 & 0.28 & 0.45 & 0.33 & 0.82 & 0.60 & 0.28 & 0 & 0 \\
\hline Min/Max & $3 / 6$ & $5 / 6$ & $5 / 6$ & $5 / 6$ & $6 / 6$ & $5 / 6$ & $4 / 6$ & $5 / 6$ & $5 / 6$ & $5 / 6$ & $4 / 6$ & $4 / 6$ & $5 / 6$ & $6 / 6$ & $6 / 6$ \\
\hline & & & & & & Age 8 & $80-84 y$ & years & & & Age & $\geq 85$ ye & ars & & \\
\hline Variable & 0 & $1-4$ & $5-8$ & $9-11$ & $\geq 12$ & 0 & $1-4$ & $5-8$ & $9-11$ & $\geq 12$ & 0 & $1-4$ & $5-8$ & $9-11$ & $\geq 12$ \\
\hline & $\overline{n=7}$ & $\overline{n=29}$ & $n=2$ & $n=4$ & $n=7$ & $\overline{n=6}$ & $n=18$ & $\overline{n=1}$ & $n=2$ & $n=0$ & $\overline{n=4}$ & $\overline{n=10}$ & $n=0$ & $n=0$ & $\mathrm{n}=0$ \\
\hline Visuospatial & & & & & & & & & & & & & & & \\
\hline Mean & 0.71 & 2.28 & 2.50 & 4.00 & 3.71 & 1.17 & 2.33 & 2.00 & 4.50 & - & 0.50 & 2.10 & - & - & - \\
\hline SD & 0.49 & 1.09 & 2.12 & 0 & 1.38 & 0.41 & 0.84 & - & 0.71 & - & 0.58 & 0.74 & - & - & - \\
\hline Min/Max & $0 / 1$ & $1 / 5$ & $1 / 4$ & $4 / 4$ & $2 / 5$ & $1 / 2$ & $1 / 4$ & $2 / 2$ & $4 / 5$ & - & $0 / 1$ & $1 / 3$ & - & - & - \\
\hline Naming & & & & & & & & & & & & & & & \\
\hline Mean & 1.86 & 2.34 & 3.00 & 2.75 & 2.43 & 1.50 & 2.28 & 3.00 & 3.00 & - & 1.50 & 2.40 & - & - & - \\
\hline $\mathrm{SD}$ & 0.69 & 0.77 & 0 & 0.50 & 0.53 & 0.55 & 0.83 & - & 0 & - & 0.58 & 0.52 & - & - & - \\
\hline Min/Max & $1 / 3$ & $0 / 3$ & $3 / 3$ & $2 / 3$ & $2 / 3$ & $1 / 2$ & $0 / 3$ & $3 / 3$ & $3 / 3$ & - & $1 / 2$ & $2 / 3$ & - & - & - \\
\hline Attention & & & & & & & & & & & & & & & \\
\hline Mean & 1.14 & 3.55 & 5.50 & 5.75 & 5.57 & 1.67 & 3.83 & 4.00 & 5.50 & - & 0.75 & 3.60 & - & - & - \\
\hline SD & 1.34 & 1.45 & 0.71 & 0.50 & 0.79 & 1.63 & 1.54 & - & 0.71 & - & 0.96 & 0.97 & - & - & - \\
\hline Min/Max & $0 / 3$ & $0 / 6$ & $5 / 6$ & $5 / 6$ & $4 / 6$ & $0 / 4$ & $1 / 6$ & $4 / 4$ & $5 / 6$ & - & $0 / 2$ & $2 / 5$ & - & - & - \\
\hline Language & & & & & & & & & & & & & & & \\
\hline Mean & 0.43 & 0.97 & 2.00 & 2.50 & 2.43 & 0.50 & 1.22 & 1.00 & 2.50 & - & 0.50 & 1.50 & - & - & - \\
\hline SD & 0.53 & 0.82 & 1.41 & 0.58 & 0.53 & 0.54 & 1.00 & - & 0.71 & - & 0.58 & 0.71 & - & - & - \\
\hline Min/Max & $0 / 1$ & $0 / 3$ & $1 / 3$ & $2 / 3$ & $2 / 3$ & $0 / 1$ & $0 / 3$ & $1 / 3$ & $2 / 3$ & - & $0 / 1$ & $0 / 2$ & - & - & - \\
\hline Abstraction & & & & & & & & & & & & & & & \\
\hline Mean & 0.43 & 0.66 & 0 & 1.25 & 1.14 & 0.50 & 0.56 & 2.00 & 0.50 & - & 0 & 0.60 & - & - & - \\
\hline SD & 0.79 & 0.77 & 0 & 0.96 & 1.07 & 0.84 & 0.70 & - & 0.70 & - & 0 & 0.69 & - & - & - \\
\hline Min/Max & $0 / 2$ & $0 / 2$ & $0 / 0$ & $0 / 2$ & $0 / 2$ & $0 / 2$ & $0 / 2$ & $2 / 2$ & $0 / 1$ & - & $0 / 0$ & $0 / 2$ & - & - & - \\
\hline Delayed reca & & & & & & & & & & & & & & & \\
\hline Mean & 1.00 & 0.97 & 0.50 & 1.00 & 3.00 & 0.83 & 0.67 & 4.00 & 1.00 & - & 0 & 0.30 & - & - & - \\
\hline SD & 1.53 & 1.48 & 0.71 & 1.41 & 1.41 & 1.33 & 1.08 & - & 1.41 & - & 0 & 0.67 & - & - & - \\
\hline Min/Max & $0 / 4$ & $0 / 4$ & $0 / 1$ & $0 / 3$ & $1 / 5$ & $0 / 3$ & $0 / 4$ & $4 / 4$ & $0 / 2$ & - & 0 & $0 / 2$ & - & - & - \\
\hline Orientation & & & & & & & & & & & & & & & \\
\hline Mean & 5.00 & 5.76 & 5.00 & 6.00 & 6.00 & 5.67 & 5.72 & 5.00 & 6.00 & - & 4.25 & 5.70 & - & - & - \\
\hline SD & 1.15 & 0.43 & 0 & 0 & 0 & 0.52 & 0.46 & - & 0 & - & 0.96 & 0.48 & - & - & - \\
\hline Min/Max & $3 / 6$ & $5 / 6$ & $5 / 5$ & $6 / 6$ & $6 / 6$ & $5 / 6$ & $5 / 6$ & $5 / 5$ & $6 / 6$ & - & $3 / 5$ & $5 / 6$ & - & - & - \\
\hline
\end{tabular}

MoCA: Montreal Cognitive Assessment; SD: standard deviation; Min/Max: minimum/maximum. 
Table 3. MoCA Total Scores and MMSE Scores, by age and education in cognitively normal participants.

\begin{tabular}{|c|c|c|c|c|c|c|c|c|}
\hline \multirow{2}{*}{ Education (years) } & \multicolumn{4}{|c|}{ MoCA } & \multicolumn{4}{|c|}{ MMSE } \\
\hline & Mean & SD & Min & Max & Mean & SD & Min & Max \\
\hline \multicolumn{9}{|l|}{ Age $60-64$ years } \\
\hline 0 & 11.75 & 5.39 & 6 & 24 & 19.83 & 3.19 & 15 & 26 \\
\hline $1-4$ & 18.53 & 4.21 & 9 & 29 & 25.55 & 2.81 & 19 & 30 \\
\hline $5-8$ & 20.91 & 4.04 & 12 & 27 & 26.27 & 2.21 & 22 & 30 \\
\hline $9-11$ & 22.53 & 3.07 & 16 & 28 & 27.33 & 1.39 & 25 & 29 \\
\hline$\geq 12$ & 24.22 & 3.32 & 17 & 30 & 27.94 & 0.99 & 26 & 30 \\
\hline \multicolumn{9}{|l|}{ Age 65-69 years } \\
\hline 0 & 12.50 & 2.79 & 9 & 17 & 21.20 & 2.39 & 18 & 25 \\
\hline $1-4$ & 18.94 & 3.54 & 11 & 26 & 25.51 & 2.31 & 21 & 29 \\
\hline $5-8$ & 21.42 & 2.76 & 15 & 26 & 26.96 & 1.39 & 24 & 30 \\
\hline $9-11$ & 22.50 & 2.88 & 16 & 26 & 27.67 & 1.83 & 25 & 30 \\
\hline$\geq 12$ & 24.35 & 2.96 & 18 & 29 & 27.53 & 1.23 & 25 & 30 \\
\hline \multicolumn{9}{|l|}{ Age $70-74$ years } \\
\hline 0 & 14.00 & 3.79 & 9 & 20 & 20.14 & 3.48 & 17 & 25 \\
\hline $1-4$ & 16.94 & 3.62 & 7 & 24 & 25.26 & 2.39 & 18 & 29 \\
\hline $5-8$ & 20.15 & 2.99 & 15 & 26 & 26.46 & 2.18 & 22 & 30 \\
\hline $9-11$ & 24.86 & 1.77 & 23 & 28 & 27.43 & 1.27 & 26 & 29 \\
\hline$\geq 12$ & 21.83 & 2.64 & 19 & 26 & 25.83 & 0.75 & 25 & 27 \\
\hline \multicolumn{9}{|l|}{ Age $75-79$ years } \\
\hline 0 & 11.57 & 3.82 & 6 & 17 & 18.57 & 2.51 & 14 & 22 \\
\hline $1-4$ & 17.52 & 3.63 & 9 & 25 & 24.38 & 2.41 & 19 & 29 \\
\hline $5-8$ & 19.50 & 4.95 & 16 & 23 & 25.00 & 1.41 & 24 & 26 \\
\hline $9-11$ & 24.25 & 1.89 & 23 & 27 & 27.75 & 1.26 & 26 & 29 \\
\hline$\geq 12$ & 24.29 & 3.20 & 20 & 28 & 27.71 & 1.70 & 26 & 30 \\
\hline \multicolumn{9}{|l|}{ Age $80-84$ years } \\
\hline 0 & 12.83 & 2.56 & 11 & 18 & 20.33 & 3.20 & 15 & 25 \\
\hline $1-4$ & 17.61 & 2.81 & 12 & 22 & 24.28 & 2.22 & 19 & 27 \\
\hline $5-8$ & 22.00 & - & 22 & 22 & 24.00 & - & 24 & 24 \\
\hline $9-11$ & 24.00 & 2.83 & 22 & 26 & 28.5 & 0.71 & 28 & 29 \\
\hline$\geq 12$ & - & - & - & - & - & - & - & - \\
\hline \multicolumn{9}{|l|}{ Age $\geq 85$ years } \\
\hline 0 & 8.50 & 2.38 & 5 & 10 & 16.75 & 0.50 & 16 & 17 \\
\hline $1-4$ & 17.20 & 2.44 & 13 & 21 & 23.50 & 1.96 & 20 & 27 \\
\hline $5-8$ & - & - & - & - & - & - & - & - \\
\hline $9-11$ & - & - & - & - & - & - & - & - \\
\hline$\geq 12$ & - & - & - & - & - & - & - & - \\
\hline
\end{tabular}

\section{Diagnostic accuracy data}

The ROC analyses revealed that the MoCA has a satisfactory accuracy to discriminate $\mathrm{CN}$ from dementia with high sensitivity (90\%) and specificity (77\%) in the total sample considering a very low cutoff score $(=15)$. When the sample was stratified among educational levels, the accuracy was higher for the group with more education, with sensitivity of $100 \%$ to detect dementia among those participants with more than four years of education. The MoCA diagnostic accuracy was lower in distinguishing $\mathrm{CN}$ from CIND in the total sample, even in the group with higher education (Table 5).

\section{DISCUSSION}

The present study aimed to provide normative data for the MoCA total and subdomain scores adjusted by age and education, including a wide range of schooling levels, including illiterates. Another aim was to investigate the diagnostic accuracy of the MoCA in a heterogeneous sample of older adults. The results indicated that the MoCA scores were significantly influenced by age, education in the three clinical groups, $\mathrm{CN}$, dementia and CIND, and by sex in the $\mathrm{CN}$ and CIND groups. The ROC analyses revealed that the MoCA had satisfactory accuracy for identifying dementia, if a low cutoff score was adopted, and low accuracy for distinguishing the normal elderly from those with CIND, especially among those with lower educational levels.

The low MoCA scores observed in this study are consistent with previous studies that also recruited heterogeneous samples of older adults ${ }^{2,11,12}$. These results confirm that the MoCA is highly reliant on abilities learned at school and that low scores may suggest educational limitations or pathology. The present normative results highlight the importance of stratifying norms according to educational level. Considering that most Brazilian seniors have four or less years of education ${ }^{24}$, providing norms for this population segment is extremely useful for clinical and research purposes. To this 
Table 4. Total and domains MoCA scores in cognitively normal participants according to the educational level comparing to MMSE total score.

\begin{tabular}{|c|c|c|c|c|c|c|c|c|c|c|c|c|c|c|c|c|}
\hline \multirow{3}{*}{ Variable } & \multicolumn{16}{|c|}{ Education (years) } \\
\hline & \multicolumn{3}{|c|}{$0(n=46)^{a}$} & \multicolumn{3}{|c|}{$1-4(n=189)^{b}$} & \multicolumn{3}{|c|}{$5-8(n=62)^{c}$} & \multicolumn{3}{|c|}{$8-11(n=40)^{d}$} & \multicolumn{3}{|c|}{$\geq 12(n=48)^{e}$} & \multirow{2}{*}{$p^{*}$} \\
\hline & Mean & SD & Median & Mean & SD & Median & Mean & SD & Median & Mean & SD & Median & Mean & SD & Median & \\
\hline Visuospatial & 1.04 & 0.59 & 1.00 & 2.30 & 1.80 & 2.00 & 2.66 & 1.16 & 3.00 & 3.60 & 0.98 & 4.00 & 3.98 & 1.16 & 4.00 & $a<b=c<d=e$ \\
\hline Naming & 1.85 & 0.63 & 2.00 & 2.34 & 0.65 & 2.00 & 2.53 & 0.65 & 3.00 & 2.70 & 0.46 & 3.00 & 2.71 & 0.46 & 3.00 & $\begin{array}{c}a<b=c=d= \\
e, b<d\end{array}$ \\
\hline Attention & 1.52 & 1.43 & 1.00 & 3.87 & 1.52 & 4.00 & 4.66 & 1.10 & 5.00 & 5.10 & 1.06 & 5.00 & 5.50 & 0.77 & 6.00 & $a<b<c=d<e$ \\
\hline Language & 0.57 & 0.69 & 0 & 1.26 & 0.85 & 1.00 & 1.35 & 0.89 & 1.00 & 2.13 & 0.69 & 2.00 & 2.25 & 0.67 & 2.00 & $a<b=c<d=e$ \\
\hline Abstraction & 0.20 & 0.50 & 0 & 0.57 & 0.72 & 0 & 1.02 & 0.86 & 1.00 & 1.18 & 0.84 & 1.00 & 1.46 & 0.82 & 2.00 & $a<b<c=d=e$ \\
\hline Delayed Recall & 0.80 & 1.44 & 0 & 0.94 & 1.40 & 0 & 1.79 & 1.61 & 1.50 & 1.60 & 1.46 & 2.00 & 2.13 & 1.58 & 2.00 & $a=b<c=d=e$ \\
\hline Orientation & 5.11 & 1.06 & 5.00 & 5.76 & 0.46 & 6.00 & 5.84 & 0.37 & 6.00 & 5.88 & 0.33 & 6.00 & 5.96 & 0.20 & 6.00 & $a<b=c=d=e$ \\
\hline MoCA Total Score & 12.09 & 3.94 & 12.00 & 18.04 & 3.68 & 18.00 & 20.92 & 3.32 & 21.50 & 23.18 & 2.76 & 23.00 & 23.98 & 3.11 & 24.00 & $a<b<c<d=e$ \\
\hline MMSE & 19.78 & 2.97 & 19.50 & 25.08 & 2.50 & 25.00 & 26.50 & 1.91 & 27.00 & 27.55 & 1.45 & 28.00 & 27.50 & 1.32 & 27.00 & $a<b<c=d=e$ \\
\hline
\end{tabular}

SD: standard deviation; MoCA: Montreal Cognitive Assessment; MMSE: Mini-Mental State Examination; *ANOVA with post hoc Bonferroni test: $p<0.001$ for all comparisons.

Table 5. MoCA cutoff scores according to the educational level and group contrast.

\begin{tabular}{|c|c|c|c|c|c|c|}
\hline Group & AUC & MoCA Cut off score & Sensitivity (\%) & Specificity (\%) & PPV (\%) & NPV (\%) \\
\hline $\begin{array}{l}\text { CN x Dementia } \\
\text { Total sample }\end{array}$ & 0.907 & 15 & 90 & 77 & 49 & 92 \\
\hline $\begin{array}{l}\text { CN x CIND } \\
\text { Total sample }\end{array}$ & 0.725 & 19 & 84 & 49 & 60 & 80 \\
\hline \multicolumn{7}{|l|}{ Dementia } \\
\hline \multicolumn{7}{|c|}{ Education (years) } \\
\hline 0 & 0.900 & 8.5 & 84 & 85 & 69 & 92 \\
\hline $1-4$ & 0.909 & 15.5 & 91 & 77 & 59 & 96 \\
\hline $5-8$ & 0.973 & 16.5 & 100 & 90 & 57 & 100 \\
\hline $9-11$ & 0.969 & 19.5 & 100 & 93 & 60 & 100 \\
\hline$\geq 12$ & 0.951 & 21.5 & 100 & 79 & 28 & 100 \\
\hline \multicolumn{7}{|l|}{ CIND } \\
\hline \multicolumn{7}{|c|}{ Education (years) } \\
\hline 0 & 0.659 & 11.5 & 81 & 56 & 45 & 86 \\
\hline $1-4$ & 0.738 & 18 & 74 & 55 & 39 & 85 \\
\hline $5-8$ & 0.642 & 19.5 & 69 & 66 & 30 & 91 \\
\hline $9-11$ & 0.781 & 19.5 & 56 & 93 & 62 & 90 \\
\hline$\geq 12$ & 0.781 & 22 & 78 & 69 & 31 & 94 \\
\hline
\end{tabular}

CN: cognitively normal; CIND: cognitive impairment, no dementia; AUC: area under curve; MoCA: Montreal Cognitive Assessment; PPV: positive predictive value; NPV: negative predictive value.

end, the MoCA Basic has been suggested as a more appropriate alternative for low educated individuals; however, the Brazilian MoCA Basic version still lacks validation ${ }^{25}$.

Some studies analyses have also indicated that older age was associated with lower MoCA scores apart from the influence of educational leve ${ }^{2,7,8}$. In the present analyses, the age effect was also observed, as mean scores among cognitively unimpaired older participants were significantly lower. This finding is most likely associated with deficits in episodic memory, working memory and visuospatial abilities known to decline with age $e^{26,27,28}$.

The sex influence in the MoCA has not been described in a previous Brazilian study ${ }^{11}$. The present results suggest that men have higher MoCA scores; however, this finding may be explained by the fact that women had a lower education in this sample. Despite this, in a Canadian study, the male sex was associated with lower MoCA scores $(p<0.001)^{8}$.
Even in recent MoCA normative data from a German speaking population with a high mean education (13.6 years), $31 \%$ of participants scored below the original cutoff $(<26$ points) and the authors found lower scores associated with older age, lower education and male $\operatorname{sex}^{29}$.

This study has limitations, mainly the fact that some age and education ranges were under-represented in the sample; for instance, there were no seniors 80 years and older with more than 12 years of education. However, the sample was representative of the sociodemographic characteristics of the population in Tremembé.

To summarize, the present study provided normative data for the MoCA, which could foster its use in clinical practice to diagnose dementia in individuals with low educational levels. The present results suggest that the MoCA may not be an adequate tool to identify individuals with CIND among those with lower education. 
1. Nasreddine ZS, Phillips NA, Bédirian V, Charbonneau S, Whitehead V, Collin I, et al. The Montreal Cognitive Assessment, MoCA: a brief screening tool for mild cognitive impairment. J Am Geriatr Soc. 2005 Apr;53(4):695-9. https://doi.org/10.1111/j.1532-5415.2005.53221.x

2. Freitas S, Simões MR, Alves L, Santana I. Montreal cognitive assessment: validation study for mild cognitive impairment and Alzheimer disease. Alzheimer Dis Assoc Disord. 2013 JanMar;27(1):37-43. https://doi.org/10.1097/WAD.0b013e3182420bfe

3. Graham JE, Rockwood K, Beattie BL, Eastwood R, Gauthier S, Tuokko H, et al. Prevalence and severity of cognitive impairment with and without dementia in an elderly population. Lancet. 1997 Jun;349(9068):1793-6. https://doi.org/10.1016/S0140-6736(97)01007-6

4. Petersen RC. Clinical practice. Mild cognitive impairment. N Engl J Med. 2011 Jun;364(23):2227-34. https://doi.org/10.1056/NEJMcp0910237

5. Roalf DR, Moberg PJ, Xie SX, Wolk DA, Moelter ST, Arnold SE. Comparative accuracies of two common screening instruments for classification of Alzheimer's disease, mild cognitive impairment, and healthy aging. Alzheimers Dement. 2013 Sep;9(5):529-37. https://doi.org/10.1016/j.jalz.2012.10.001

6. Luis CA, Keegan AP, Mullan M. Cross validation of the Montreal Cognitive Assessment in community dwelling older adults residing in the Southeastern US. Int J Geriatr Psychiatry. 2009 Feb;24(2):197201. https://doi.org/10.1002/gps.2101

7. Malek-Ahmadi M, Powell JJ, Belden CM, O'Connor K, Evans L, Coon DW, et al. Age- and education-adjusted normative data for the Montreal Cognitive Assessment (MoCA) in older adults age 70-99. Neuropsychol Dev Cogn B Aging Neuropsychol Cogn. 2015;22(6):75561. https://doi.org/10.1080/13825585.2015.1041449

8. Larouche E, Tremblay MP, Potvin O, Laforest S, Bergeron D, Laforce R, et al. Normative data for the Montreal cognitive assessment in middle-aged and elderly Quebec-French people. Arch Clin Neuropsychol. 2016 Sep;31(7):819-26. https://doi.org/10.1093/arclin/acw076

9. Carson N, Leach L, Murphy KJ. A re-examination of Montreal Cognitive Assessment (MoCA) cutoff scores. Int J Geriatr Psychiatry. 2018 Feb;33(2):379-88. https://doi.org/10.1002/gps.4756

10. Memória CM, Yassuda MS, Nakano EY, Forlenza OV. Brief screening for mild cognitive impairment: validation of the Brazilian version of the Montreal cognitive assessment. Int J Geriatr Psychiatry. 2013 Jan;28(1):34-40. https://doi.org/10.1002/gps.3787

11. Apolinario D, Dos Santos MF, Sassaki E, Pegoraro F, Pedrini AV, Cestari B, et al. Normative data for the Montreal Cognitive Assessment (MoCA) and the Memory Index Score (MoCA-MIS) in Brazil: adjusting the nonlinear effects of education with fractional polynomials. Int J Geriatr Psychiatry. 2018 Jul;33(7):893-9. https://doi.org/10.1002/gps.4866

12. Gómez F, Zunzunegui M, Lord C, Alvarado B, García A. Applicability of the MoCA-S test in populations with little education in Colombia. Int J Geriatr Psychiatry. 2013 Aug;28(8):813-20. https://doi.org/10.1002/gps.3885

13. César KG, Brucki SM, Takada LT, Nascimento LF, Gomes CM, Almeida MC, et al. Prevalence of Cognitive Impairment Without Dementia and Dementia in Tremembé, Brazil. Alzheimer Dis Assoc Disord. 2016 JulSep;30(3):264-71. https://doi.org/10.1097/WAD.0000000000000122

14. McKhann GM, Knopman DS, Chertkow H, Hyman BT, Jack CR Jr, Kawas $\mathrm{CH}$, et al. The diagnosis of dementia due to Alzheimer's disease: recommendations from the National Institute on AgingAlzheimer's Association workgroups on diagnostic guidelines for
Alzheimer's disease. Alzheimers Dement. 2011 May;7(3):263-9. https://doi.org/10.1016/j.jalz.2011.03.005

15. Frota NA, Nitrini R, Damasceno BP, Forlenza O, Dias-Tosta E, Silva AB et al. Critérios para o diagnóstico de doença de Alzheimer. Dement Neuropsychol. 2011;5 Suppl 1:5-10.

16. Jorm AF. A short form of the Informant Questionnaire on Cognitive Decline in the Elderly (IQCODE): development and cross-validation. Psychol Med. 1994 Feb;24(1):145-53. https://doi.org/10.1017/S003329170002691X

17. Perroco TR, Bustamante SE, Moreno MP, Hototian SR, Lopes MA, Azevedo D, et al. Performance of Brazilian long and short IQCODE on the screening of dementia in elderly people with low education. Int Psychogeriatr. 2009 Jun;21(3):531-8. https://doi.org/10.1017/S1041610209008849

18. Pfeffer RI, Kurosaki TT, Harrah CH Jr, Chance JM, Filos S. Measurement of functional activities in older adults in the community.J Gerontol. 1982 May;37(3):323-9. https://doi.org/10.1093/geronj/37.3.323

19. Folstein MF, Folstein SE, McHugh PR. "Mini-mental state": a practical method for grading the cognitive state of patients for the clinician. J Psychiatr Res. 1975 Nov;12(3):189-98. https://doi.org/10.1016/0022-3956(75)90026-6

20. Brucki SM, Nitrini R, Caramelli P, Bertolucci PH, Okamoto IH. [Suggestions for utilization of the mini-mental state examination in Brazil[. Arq Neuropsiquiatr. 2003 Sep;61(3B):777-81. Portuguese. https://doi.org/10.1590/S0004-282X2003000500014

21. Nitrini R, Lefèvre BH, Mathias SC, Caramelli P, Carrilho PE, Sauaia N, et al. [Neuropsychological tests of simple application for diagnosing dementia]. Arq Neuropsiquiatr. 1994 Dec;52(4):457-65. Portuguese. https://doi.org/10.1590/S0004-282X1994000400001

22. Brucki SM, Malheiros SM, Okamoto IH, Bertolucci PH. [Normative data on the verbal fluency test in the animal category in our milieu]. Arq Neuropsiquiatr. 1997 Mar;55(1):56-61. Portuguese. https://doi.org/10.1590/S0004-282X1997000100009

23. Caramelli P, Carthery-Goulart MT, Porto CS, Charchat-Fichman H, Nitrini R. Category fluency as a screening test for Alzheimer disease in illiterate and literate patients. Alzheimer Dis Assoc Disord. 2007 Jan-Mar;21(1):65-7. https://doi.org/10.1097/WAD.0b013e31802f244f

24. Instituto Brasileiro de Geografia e Estatística - IBGE. Database 2017. [cited 2018 oct 2]. Available from: https://sidra.ibge.gov.br/ tabela/3540\#resultado

25. Julayanont P, Tangwongchai S, Hemrungrojn S, Tunvirachaisakul C, Phanthumchinda K, Hongsawat J, et al. The Montreal Cognitive Assessment-Basic: a screening tool for mild cognitive impairment in illiterate and low-educated elderly adults. J Am Geriatr Soc. 2015 Dec;63(12):2550-4. https://doi.org/10.1111/jgs.13820

26. Salthouse TA. Selective review of cognitive aging. J Int Neuropsychol Soc. 2010 Sep;16(5):754-60. https://doi.org/10.1017/S1355617710000706

27. Nyberg L, Lövdén M, Riklund K, Lindenberger U, Bäckman L. Memory aging and brain maintenance. Trends Cogn Sci. 2012 May;16(5):292305. https://doi.org/10.1016/j.tics.2012.04.005

28. Techentin C, Voyer D, Voyer SD. Spatial abilities and aging: a meta-analysis. Exp Aging Res. 2014;40(4):395-425. https://doi.org/10.1080/0361073X.2014.926773

29. Thomann AE, Goettel N, Monsch RJ, Berres M, Jahn T, Steiner LA, et al. The Montreal Cognitive Assessment: Normative Data from a German-Speaking Cohort and Comparison with International Normative Samples. J Alzheimers Dis. 2018;64(2):643-55. https://doi.org/10.3233/JAD-180080 